\title{
Immunotherapy in Advanced Head and Neck Squamous Cell Carcinoma: A Retrospective Evaluation in Latin America
} \author{
Raul $^{8}$ \\ ${ }^{1}$ Department of Head and Neck Medical Oncology, Instituto Alexander Fleming, Argentina \\ ${ }^{2}$ Department of Medical Oncology Instituto Alexander Fleming, Argentina \\ ${ }^{3}$ Department of Head and Neck Medical Oncology, Hospital Italiano, Argentina \\ ${ }^{4}$ Department of Head and Neck Medical Oncology, Hospital Aleman, Argentina \\ ${ }^{5}$ Department of Head and Neck Medical Oncology, Hospital Posadas, Argentina \\ ${ }^{6}$ Department of Radiation Oncology, CAIPO, Tucuman, Argentina \\ ${ }^{7}$ Department of Head and Neck Medical Oncology, CAIPO, Tucuman, Argentina \\ ${ }^{8}$ Department of Head and Neck Medical Oncology Instituto Angel Roffo, Argentina \\ ${ }^{9}$ Department of Radiation Oncology Instituto Angel Roffo, Argentina
}

Falco Agustin $\mathrm{H}^{1 *}$, Angel Martin $\mathbf{0}^{1}$, Pérez Felipe $\mathrm{J}^{2}$, Cayol Federico ${ }^{3}$, Gomez Abuin ${ }^{4}$, Gonzalo, Adelchanow ${ }^{5}$, Eduardo Palazzo ${ }^{6}$, Jorge L ${ }^{7}$, Palazzo Felipe ${ }^{8}$, Pereira David ${ }^{9}$, Carrera Juan ${ }^{8} \mathrm{M}_{\text {and }}$ Giglio

*Corresponding author: Agustin H Falco, Department of Head and Neck Medical Oncology, Instituto Alexander Fleming, Argentina

\section{ARTICLE INFO}

Received: 㓞 April 14, 2019

Published: 蔧 April 23, 2019

Citation: Falco Agustin H, Angel M O, Pérez Felipe J, Cayol F, Gomez A, et al. Immunotherapy in Advanced Head and Neck Squamous Cell Carcinoma: A Retrospective Evaluation in Latin America. Biomed J Sci \& Tech Res 17(2)-2019. BJSTR. MS.ID.002983.

Keywords: Head and Neck Cancer; Immunotherapy; Immune Checkpoint Inhibitors; Real-World; Latin America.

\section{ABSTRACT}

The standard of care in first line treatment for advanced Head and Neck Squamous Cell Carcinoma (SCCHN) includes polychemotherapy based on platinum and Cetuximab. In recent years, and with results from 2 phase III studies, immunotherapy (antiPD1/ PDL1) has proved to be effective and with a manageable toxicity profile in patients (pts) progressed to platinum. To describe the clinical-pathological characteristics, efficacy (overall survival -OS-, objective response rates -ORR- and progression free survival -PFS-) and toxicity of pts with advanced SCCHN treated with immunotherapy. A retrospective multinstitutional descriptive analysis of pts treated with immunotherapy for advanced SCCHN from 03/2017 to 05/2018, in Argentinian academic centers. Treatment setting were defined as Platinum refractory (progression within 6 months after multimodal therapy using platinum regimen); first and subsequent lines for metastatic disease. Forty $(\mathrm{N})$ pts with were included with a median (md) age of 63.8 years (r: 36-84), 28 (70\%) male, $90 \%$ exposure to tobacco, 17\% HPV positive. Location: Oropharynx 35\% ( $\mathrm{n}=14)$ Oral cavity $30 \%(n=12)$, larynx / hypopharynx 35\% ( $=14)$. Performance status (PS) 0-1: 72\%, 2: 22\%. Immunotherapy indication: Platinum refractory: $n=12(30 \%), 2^{\circ}$ line $\mathrm{n}=21(52 \%), 3^{\circ}$ line $\mathrm{n}=7(17 \%)$. Treatment: Nivolumab $18 \mathrm{pts}(45 \%)$, Pembrolizumab 20 (50\%), Durvalumab 2 (5\%). Previous Cetuximab use: 17 pts (42\%). Toxicity: Grade 1-2: $70 \%$ (n 28) Grade 3-4: 12.5\% (n 5). ORR: 33\%, md PFS: 13.9 months (m) (95\% CI: 9.5-23.4), md OS $22.9 \mathrm{~m}$ (95\% CI .14.8-NA). The results of this study are shown in agreement with what is evidenced in the literature, with a higher proportion of pts with fewer previous treatment lines. Despite the weakness for being a retrospective analysis, it highlights the multi-institutional cooperation, relevant for the study of this pathology. 


\section{Introduction}

Squamous Cell Carcinoma of the Head and Neck (SCCHN) includes neoplasms in the oral cavity, pharynx and larynx and accounts for $90 \%$ of all head and neck cancers [1-3]. Despite multimodal therapy including platinum-based chemoradiotherapy, more than $50 \%$ of patients with locoregionally advanced SCCHN have recurrence or develop metastases (or both) within 3 years of treatment [4-6]. Patients with recurrent/metastatic (R/M) SCCHN who progress within 6 months after platinum-based therapy have poor long-term prognosis and limited treatment options, with a median Overall Survival (OS) of $\leq 6$ months [7,8]. Platinumbased combination chemotherapy regimens and cetuximab are commonly used in the first-line recurrent and metastatic settings [9]. Until 2017, treatment options for recurrent and metastatic disease following progression on a platinum-based regimen were limited to single-agent chemotherapy or cetuximab, which yield a median overall survival of 7 months or less [10-12].

Inhibitors of the Programmed Death 1 (PD-1) pathway, which is implicated in tumor immune escape, have emerged as valid treatment options in patients with squamous cell carcinoma of the head and neck based on their antitumor activity and safety profiles [13-19]. On the basis of these data, we initiated a retrospective, multinstitutional, descriptive analysis, to evaluate the efficacy and safety of different immunotherapeutic drugs, in a "real world" subset of patients with R/M SCCHN that progressed during or after platinum-based chemotherapy.

\section{Objectives}

To describe the clinical-pathological characteristics, efficacy (overall survival -OS-, objective response rates -ORR- and Progression Free Survival -PFS-) and toxicity of pts with advanced SCCHN treated with immunotherapy.

\section{Methods}

Retrospective multinstitutional descriptive analysis of patient treated with immunotherapy for advanced SCCHN from 03/2017 to $05 / 2018$, in Argentinian academic centers (Hospital Alemán, Hospital Italiano de Buenos Aires, Instituto Ángel Roffo, Hospital Posadas, Instituto Alexander Fleming and Centro de Atención Integral del Paciente Oncológico Tucuman). Treatment setting were defined as Platinum refractory (progression within 6 months after multimodal therapy using platinum regimen); first and subsequent lines for metastatic disease. Statistix 8.0 was used for statistical analysis. Descriptive statistics (including mean, standard deviation, median, range, frequency, and percentage) were calculated to characterize the patient population. Tumor responses were measured radiographically using Response Evaluation Criteria for Solid Tumors (RECIST) version 1.1. Follow-up assessments were conducted by telephone or at the outpatient clinic. Survival time was calculated from the date of diagnosis until the date of last contact or death. The Kaplan-Meier method was used to assess the survival outcome. Univariate and multivariate analyses were performed using Cox regression. Hazard Ratios (HRs) and 95\% Confidence Intervals (CIs) were calculated.

\section{Results}

From March 2017 through May 2018, 40 patients from 6 hospitals in Argentina were included for analysis. Among baseline characteristics, patients presented with a median age of 63,8 years old, predominately male 70\%. ECOG performance status between 0 -1 was observed in 28 patients $(72 \%)$. The most frequent location of primary tumor was oropharynx 14 (35\%) follow by oral cavity $(27,5 \%)$, larynx (25\%) and hypopharynx (10\%). HPV evaluation was only done in $47 \%$ (19) of patients, being positive in $17 \%$. All patients presented squamous cell carcinoma. PDL1 test was not performed in any patient (Table 1). Most of the immunotherapy indication was as second line treatment 53\% (21), 30\% (12) in refractory setting and only $17 \%$ (7) in third line. The first line treatment was EXTREME (Platinum-5Fu-Cetuximab) in $45 \%$ (18), TPEx (Platinum - Docetaxel - Cetuximab) 12\% (5) and other platinum-based chemotherapy in $43 \%$ (17) patients. The checkpoint inhibitors used were Pembrolizumab in 50\% (20), Nivolumab in 45\% (18), and Durvalumab in 5\% (2) of patients.

Table 1: Demographics and clinicopathological features.

\begin{tabular}{|c|c|}
\hline & $\mathrm{N}=40$ \\
\hline Age (years) & $63(36-84)$ \\
\hline \multicolumn{2}{|l|}{ Sex } \\
\hline Male; n (\%) & $28(70 \%)$ \\
\hline Female; n (\%) & $12(30 \%)$ \\
\hline \multicolumn{2}{|c|}{ Tabacco } \\
\hline Never; n (\%) & $36(90 \%)$ \\
\hline Current/former; n (\%) & $4(10 \%)$ \\
\hline \multicolumn{2}{|c|}{ HPV status } \\
\hline Positive; n (\%) & $7(17 \%)$ \\
\hline Negative; $\mathrm{n}(\%)$ & $12(30 \%)$ \\
\hline Not evaluated; n (\%) & $21(52 \%)$ \\
\hline \multicolumn{2}{|c|}{ Tumor Location } \\
\hline Oropharynx; n (\%) & $14(35 \%)$ \\
\hline Oral Cavity; n (\%) & $11(27.5 \%)$ \\
\hline Larynx; n (\%) & $10(25 \%)$ \\
\hline Hypopharynx; n (\%) & $4(10 \%)$ \\
\hline \multicolumn{2}{|c|}{ ECOG PerformanceStatus (PS) } \\
\hline $0-1 ; n(\%)$ & $28(72 \%)$ \\
\hline $2-3 ; n(\%)$ & $12(22 \%)$ \\
\hline
\end{tabular}

With a median duration of follow up of 6 months, and a median of 8 cycles of immunotherapy, 55\% (22) patients achieved clinical benefit. Partial response seen in $25 \%$ (10), stable disease $22 \%$ (9), Complete response in $8 \%$ (3) of the patients. The mean duration of the response was 7,1 months (r:5-10). Among the $45 \%$ (18) patients that presented progression of the disease, the most frequent location of relapse/progression was locoregional. Fortyfive percent of the patients (18) died. The median Progression Free Survival (PFS) was 13.9 months (95\%IC:9.5-23.4). The median Overall Survival (OS): was 22,9 months (95\%IC:14.8-NR). The 12 -month overall survival was $76 \%$ (Figures $1 \& 2$ ). The treatmentrelated grade 1 and 2 Adverse Events (AE) occurred in 70\% (28) 
of the patients Grade 3 and 4 adverse events were seen in $12 \%$ (5). No grade 5 adverse event reported. Among the adverse events that lead to drug discontinuation were pneumonitis and nephritis in $3(7,5 \%)$ patients. Corticosteroids were required in $17,5 \%(7)$ patients. No other immunosuppressive agent was needed to treated the adverse events (Table 2).

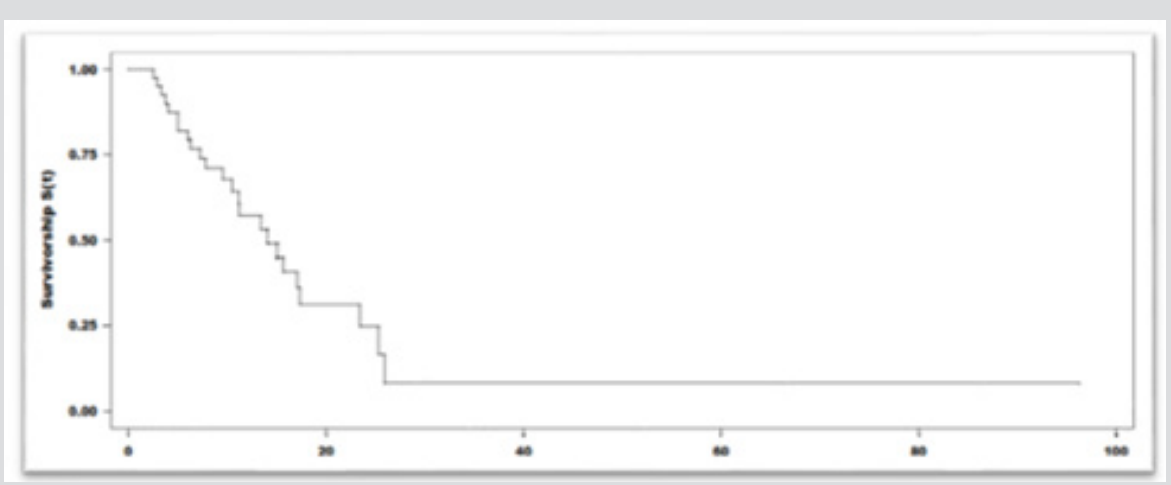

Graph 1: Progression Free survival. Kapplan-meier curve. Event: progression. Time: months.

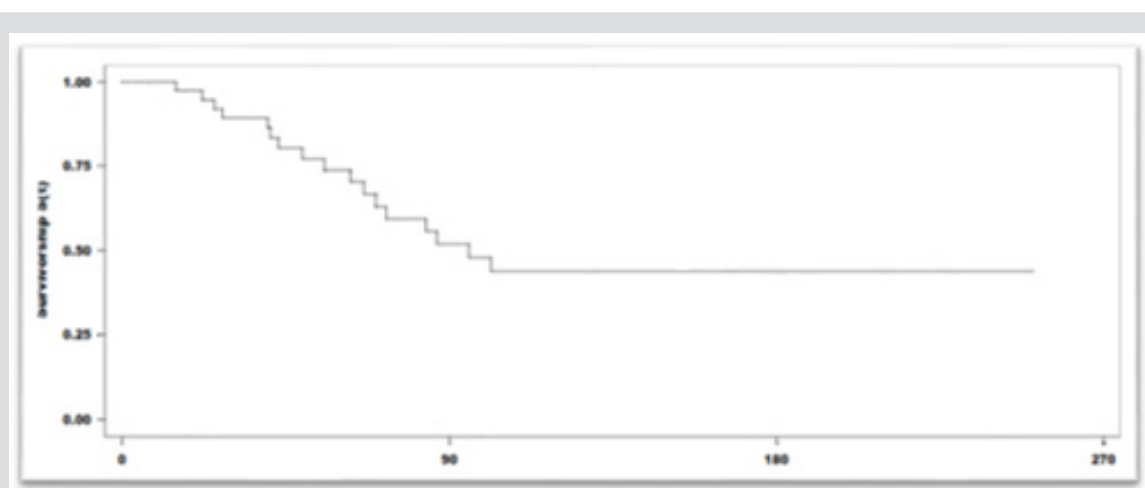

Graph 2: Overall survival. Kapplan-meier curve. Event: death. Time: months.

Table 2: Toxicity profile.

\begin{tabular}{|c|c|c|}
\hline Grade & $\mathrm{N}=40$ & \\
\hline $1-2 ; \mathrm{n}(\%)$ & $28(70 \%)$ & \\
\hline $3-4 ; \mathrm{n}(\%)$ & $12(30 \%)$ & \\
\hline \multicolumn{3}{|c|}{ Immune related adverse event } \\
\hline Event & Grade $1-2$ & Grade3-4 \\
\hline Asthenia; n (\%) & $19(47 \%)$ & $1(2,5 \%)$ \\
\hline Fatigue; n (\%) & $13(32 \%)$ & 0 \\
\hline Diarrhea; n (\%) & $5(12 \%)$ & $1(2,5 \%)$ \\
\hline Rash; n (\%) & $2(5 \%)$ & 0 \\
\hline Pruritus; n (\%) & 0 & $1(2,5 \%)$ \\
\hline Arthralgias; n (\%) & $4(10 \%)$ & 0 \\
\hline Myalgia; n (\%) & $4(10 \%)$ & $2(5 \%)$ \\
\hline Thyroiditis; n (\%) & $2(5 \%)$ & 0 \\
\hline Pneumonitis; n (\%) & 0 & $2(5 \%)$ \\
\hline Nephritis; n (\%) & 0 & $1(2,5 \%)$ \\
\hline \multirow{2}{*}{$\begin{array}{l}\text { Drug discontinuation; } \\
\text { n (\%) }\end{array}$} & & \\
\hline & \multicolumn{2}{|c|}{$3(7,5 \%)$} \\
\hline \multirow{2}{*}{$\begin{array}{l}\text { Use Corticosteroids; } \\
\mathrm{n}(\%)\end{array}$} & & \\
\hline & \multicolumn{2}{|c|}{$7(17,5)$} \\
\hline
\end{tabular}

\section{Discussion}

The prognosis of patients with recurrent or metastatic head and neck squamous cell cancer is generally poor. The median survival, in most series, is 6 to 12 months depending upon patient and diseaserelated factors. Systemic therapy is indicated in conjunction with best supportive care for most patients with metastatic or advanced recurrent head and neck cancer. The choice of a systemic regimen is influenced by whether patients have received prior treatment as part of a combined modality approach postoperatively or for functional organ preservation as part of their initial management or whether they had previously received systemic therapy for metastatic or recurrent locoregional disease. Treatment options include single-agent therapy and combination regimens using either conventional cytotoxic chemotherapy and/or molecularly targeted agents combined with best supportive care. Checkpoint inhibitor immunotherapy is an option for patients with progressive disease after their initial chemotherapy regimen.

Pembrolizumab and nivolumab, checkpoint inhibitors of programmed cell death protein 1 (PD-1), have shown clinically significant activity in patients who progressed on or after platinumbased regimens and these agents are approved for this indication $[15,17]$. In this group of patients, there was no difference related to the Human Papilloma Virus (HPV) status. Treatment is associated with immune-related adverse events (irAEs) that typically are transient but occasionally can be severe or fatal. The most common 
and important irAEs are dermatologic, diarrhea/colitis and endocrinopathies [15,17]. Patient-reported outcomes on a quality of life questionnaire found that there was no clinically meaningful deterioration associated with treatment with nivolumab immunotherapy, in contrast to chemotherapy, where quality of life significantly decreased in 8 of 15 domains [20].

For those with R/M SCCHN without prior exposure to systemic therapy, the combination of pembrolizumab plus chemotherapy improves overall survival beyond that seen with cetuximab plus chemotherapy. For those with high Programmed Cell Death ligand 1 (PD-L1) expression, single-agent pembrolizumab also improves overall survival compared with cetuximab plus chemotherapy. These results have been presented in abstract form, and regulatory authorities are evaluating the use of pembrolizumab for this indication [21]. The results of this descriptive analysis solidify the role of PD-1 checkpoint inhibition in the treatment of head and neck squamous cell carcinoma. Of course, our results should be assessed critically. Limitations of the data include the retrospective evaluation. Despite of the small sample size, our data are in accordance with the published one, with a higher proportion of patients with fewer previous treatment lines. Another weakness of the study is the lack of a biomarker analysis (not required for the use of these drugs in this pathology in the second line or after). At the other hand, In spite of the weakness for being a retrospective analysis, it highlights the multi-institutional cooperation, relevant for the study of this disease. To our knowledge, this is the first published experience with a "real world" group of patients with R/M SCCHN in Latin America.

\section{References}

1. Ferlay J, Soerjomataram I, Dikshit R, Eser S, Mathers C, Rebelo M, et al. (2015) Cancer incidence and mortality worldwide: sources, methods and major patterns in GLOBOCAN 2012. Int J Cancer 136(5): E359-386.

2. Wissinger E, Griebsch I, Lungershausen J, Foster T, Pashos CL (2014) The economic burden of head and neck cancer: a systematic literature review. Pharmacoeconomics 32(9): 865-882.

3. Vigneswaran N, Williams (2014) Epidemiologic trends in head and neck cancer and aids in diagnosis. Oral Maxillofac Surg Clin North Am 26(2): 123-141.

4. Licitra L, Felip E, Group EGW (2009) Squamous cell carcinoma of the head and neck: ESMO clinical recommendations for diagnosis, treatment and follow-up. Ann Oncol 20(suppl 4): 121-122.

5. National Comprehensive Cancer Network I (2018) NCCN clinical practice guidelines in oncology (NCCN guidelines): head and neck cancers, version 2 .

6. Blanchard P, Baujat B, Holostenco V, Bourredjem A, Baey C et al. (2011) Meta-analysis of chemotherapy in head and neck cancer (MACH-NC): a comprehensive analysis by tumour site. Radiother Oncol 100(1): 33-40.

7. Bernier J (2008) Drug Insight: cetuximab in the treatment of recurrent and metastatic squamous cell carcinoma of the head and neck. Nat Clin Pract Oncol 5: 705-713.
8. Saloura V, Cohen EE, Licitra L, Billan S, Dinis J, et al. (2014) An openlabel singlearm, phase II trial of zalutumumab, a human monoclonal anti-EGFR antibody, in patients with platinum-refractory squamous cell carcinoma of the head and neck. Cancer Chemother Pharmacol 73(6): 1227-1239.

9. Vermorken JB, Mesia R, Rivera F, Eva Remenar, Andrzej Kawecki, et al. (2008) Platinum-based chemotherapy plus cetuximab in head and neck cancer. N Engl J Med 359: 1116-1127.

10. Guardiola E, Peyrade F, Chaigneau L, Tchiknavorian X, Bompas E, et al. (2004) Results of a randomized phase II study comparing docetaxel with methotrexate in patients with recurrent head and neck cancer. Eur J Cancer 40(14): 2071-2076.

11. Vermorken JB, Herbst RS, Leon X, Amellal N, Baselga J (2008) Overview of the efficacy of cetuximab in recurrent and/or metastatic squamous cell carcinoma of the head and neck in patients who previously failed platinum-based therapies. Cancer 112(12): 2710-2719.

12. Argiris A, Ghebremichael M, Gilbert J, Lee JW, Sachidanandam K, et al. (2013) Phase III randomized, placebo-controlled trial of docetaxel with or without gefitinib in recurrent or metastatic head and neck cancer: an eastern cooperative oncology group trial. J Clin Oncol 31(11): 14051414.

13. Seiwert TY, Burtness B, Mehra R, Weiss J, Berger R, et al. (2016) Safety and clinical activity of pembrolizumab for treatment of recurrent or metastatic squamous cell carcinoma of the head and neck (KEYNOTE-012): an open-label, multicentre, phase 1b trial. Lancet Oncol 17(7): 956-965.

14. Chow LQ, Haddad R, Gupta S, Mahipal A, Mehra R, et al. (2016) Antitumor activity of pembrolizumab in biomarker-unselected patients with recurrent and/or metastatic head and neck squamous cell carcinoma: Results from the phase Ib KEYNOTE-012 expansion cohort. J Clin Oncol 34(32): 3838-3845.

15. Ferris RL, Blumenschein G, Fayette J, Guigay J, Colevas AD, et al. (2016) Nivolumab for recurrent squamous-cell carcinoma of the head and neck. N Engl J Med 375: 1856-1867.

16. Moy JD, Moskovitz JM, Ferris RL (2017) Biological mechanisms of immune escape and implications for immunotherapy in head and neck squamous cell carcinoma. Eur J Cancer 76: 152-166.

17. Bauml J, Seiwert TY, Pfister DG, Worden F, Liu SV, et al. (2017) Pembrolizumab for platinum- and cetuximab-refractory head and neck cancer: results from a single-arm, phase II study. J Clin Oncol 35(14): 1542-1549.

18. Bahleda R, Braiteh FS, Balmanoukian AS, I Braña, FS Hodi, et al. (2017) Long-term safety and clinical outcomes of atezolizumab in head and neck cancer: phase Ia trial results. Ann Oncol 28 (suppl 5): v372-v394.

19.Zandberg D, Algazi A, Jimeno A, JS Good, J Fayette, et al. (2017) Durvalumab for recurrent/ metastatic (R/M) head and neck squamous cell carcinoma (HNSCC): preliminary results from a single-arm, phase 2 study. Ann Oncol 28 (suppl 5): v372-v394.

20. Harrington KJ, Ferris RL, Blumenschein G, Colevas AD, Fayette J, et al. (2017) Nivolumab versus standard, single-agent therapy of investigator's choice in recurrent or metastatic squamous cell carcinoma of the head and neck (CheckMate 141): health-related quality-of-life results from a randomised, phase 3 trial. Lancet Oncol 18(8): 1104-1115.

21. Burtness B, Harrington KJ, Greil R, D Soulières, M Tahara, et al. (2018) KEYNOTE-048: Phase 3 study of first-line pembrolizumab for recurrent/ metastatic head and neck squamous cell carcinoma (abstract). Presented at ESMO 2018 Trial NCT02358031. 


\section{ISSN: 2574-1241}

DOI: 10.26717/BJSTR.2019.17.002983

Agustin H Falco. Biomed J Sci \& Tech Res

CC This work is licensed under Creative

Submission Link: https://biomedres.us/submit-manuscript.php

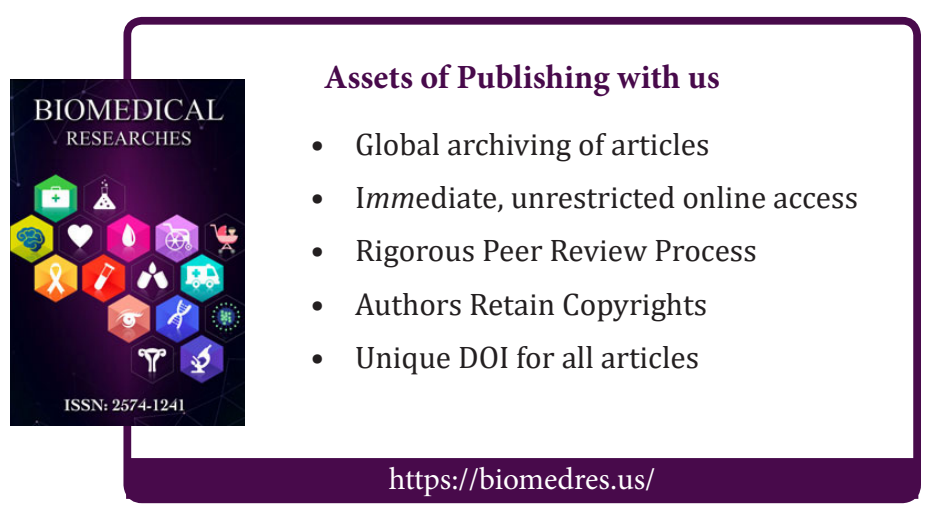

